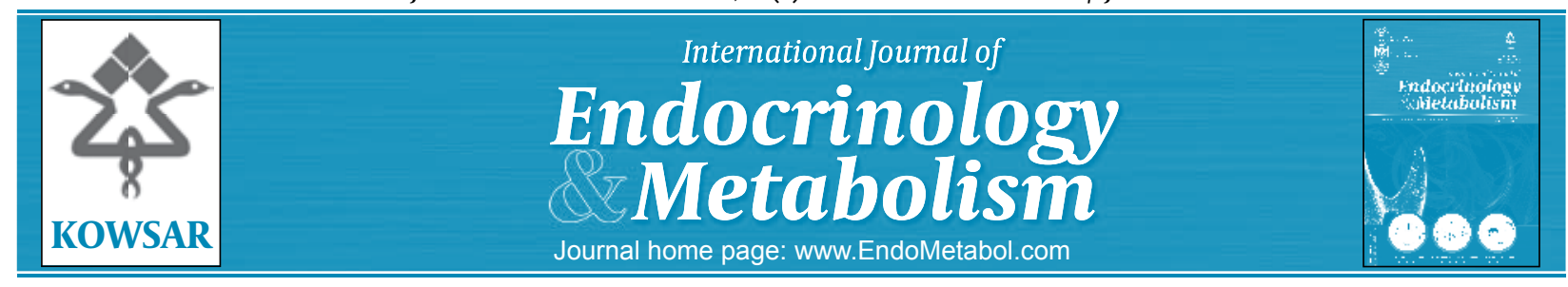

\title{
Primary Hypothyroidism: Uncommon Presentation With Reversible Dilated Cardiomyopathy in a Young Subject
}

\author{
Sunil Kumar Kota ${ }^{1^{*}}$, Prabhas Ranjan Tripathy ${ }^{2}$, Siva Krishna Kota ${ }^{3}$, Sruti Jammula ${ }^{4}$, Lalit \\ Kumar Meher ${ }^{5}$, Kirtikumar Dharmshibhai Modi ${ }^{1}$ \\ ${ }^{1}$ Department of Endocrinology, Medwin Hospital, Hyderabad, Andhra Pradesh, India \\ ${ }^{2}$ Department of Anatomy, Kalinga Institute of Medical Sciences, Bhubaneswar, Orissa, India \\ ${ }^{3}$ Department of Anesthesia, Central Security Hospital, Riyadh, Saudi Arabia \\ ${ }^{4}$ Department of Pharmaceutics, Roland Institute of Pharmaceutical sciences, Berhampur, Orissa, India \\ ${ }^{5}$ Department of Medicine, MKCG Medical College, Berhampur, Orissa, India
}

\begin{tabular}{|c|c|}
\hline A R T I C L E I N F O & A B S T R A C T \\
\hline Article type: & \multirow{7}{*}{$\begin{array}{l}\text { Most patients with dilated cardiomyopathy have a poor prognosis that is associated with } \\
\text { progressive and irreversible myocardial dysfunction. Rarely, a reversible metabolic eti- } \\
\text { ology that is amenable to specific therapy is identified. Thyroid hormones have many } \\
\text { effects on the heart. Although cardiac output is reduced in hypothyroidism, heart failure } \\
\text { is relatively rare due to the lower demand for peripheral oxygen delivery. We report a } \\
\text { 14-year-old girl who presented with dilated cardiomyopathy (DCM) and was determined } \\
\text { to have primary hypothyroidism, for whom cardiac function improved significantly af- } \\
\text { ter levothyroxine replacement therapy. Our case underscores the necessity of thyroid } \\
\text { function testing to examine the etiology of nonischemic DCM, even in young subjects. }\end{array}$} \\
\hline Case Report & \\
\hline Article history: & \\
\hline Received: 25 Sep 2011 & \\
\hline Revised: 20 Dec 2011 & \\
\hline Accepted: 28 Dec 2011 & \\
\hline & \\
\hline
\end{tabular}

Dilated Cardiomyopathy

Hypothyroidism

Levothyroxine

Copyright $\odot 2012$ Kowsar M. P. Co. All rights reserved.

- Implication for health policy/practice/research/medical education:

Hypothyroidism is a rare cause of dilated cardiomyopathy and hormonal treatment with levothyroxine can significantly improve myocardial function. Hence it is felt that thyroid function tests should be systematically performed in all patients with DCM in order to rule out hypothyroidism.

- Please cite this paper as:

Kumar Kota S, Tripathy PR, Krishna Kota S, Jammula S, Kumar Meher L, Modi KD, Primary Hypothyroidism: Uncommon Presentation With Reversible Dilated Cardiomyopathy in a Young Subject. Int JEndocrinol Metab. 2012;10(1): 440-3. DOI: 10.5812/ijem.2382

\section{Introduction}

Cardiomyopathies constitute a group of diseases that primarily affect the heart muscle and are not the result of congenital, acquired valvular, hypertensive coronary arterial, or pericardial abnormalities. Dilated cardiomyopathy (DCM) is an idiopathic condition that results from impaired ventricular systolic function, leading to progressive cardiac remodeling and dilatation (1). A reversible form of DCM can develop

* Corresponding author: Sunil Kumar Kota, Department of Endocrinology, Medwin Hospitals, Chiragh Ali Lane, Nampally, Hyderabad-500001, Andhra Pradesh, India. Tel: +91-9959369777, Fax: +91-40 66623441, E-mail: hidocsunil@ibibo.com

DOI:10.5812/ijem.2382

Copyright $\odot 2012$ Kowsar M. P. Co. All rights reserved. due to alcohol use, pregnancy, chronic uncontrolled tachycardia, hypothyroidism, hyperthyroidism, drug use, and other endocrine dysfunctions (2-7). Since the first description of DCM in 4 hypothyroid patients in 1918, few such cases have been published $(8,9)$; most reports have described adults, the youngest of whom was 20 years (8). We report a case of hypothyroidism in a young patient with DCM.

\section{Case report}

A 14-year-old girl complained of dyspnea on exertion for 1 month. The dyspnea was progressive, with the patient becoming symptomatic at gradually lower levels of exertion. She had a history of 3 episodes of paroxysmal nocturnal dyspnea without any chest pain or syncope. Over the past 
15 days, she developed increasing pedal edema. In the past year, the patient noticed weight gain, facial puffiness, constipation, dry skin, and intolerance to cold.

On examination, the patient was obese, with a body mass index (BMI) of $28.4 \mathrm{~kg} / \mathrm{m}^{2}$, and her skin was pale and dry. Her blood pressure was $120 / 80 \mathrm{~mm} \mathrm{Hg}$, and her pulse was $54 / \mathrm{min}$. We noted bilateral pitting pedal edema with raised jugular venous pressure. A symmetrical and firm grade 2 goiter was palpable. Bilateral ankle jerks showed delayed relaxation. Heart sounds were distant, with a chest examination revealing bibasilar end inspiratory crackles and an abdominal examination showing tender hepatomegaly. A chest $\mathrm{x}$-ray showed cardiomegaly and a reverse bat wing appearance of a pulmonary edema (Figure 1). There were nonspecific ST-T changes with low voltage QRS complexes on the electrocardiogram. Echocardiography revealed a DCM with severe dysfunction of the left ventricle (ejection fraction 25\%) and global hypokinesia (Figure 2).

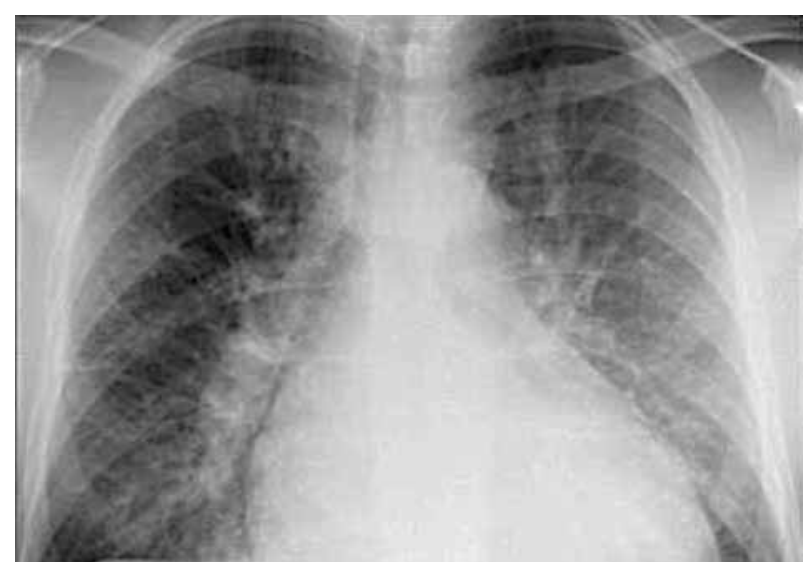

$\overline{\text { Figure 1. Chest X Ray PA View Showing Cardiomegaly and Reverse bat }}$ Wing Appearance of Pulmonary Edema.

Figure 2. Apical Four Chamber Echocardiographic View Shows Marked Enlargement of all Four Chambers, as Well as Spontaneous Echo Contrast in the Left Sided Chambers Because of a Very low Ejection Fraction and Sluggish Flow.

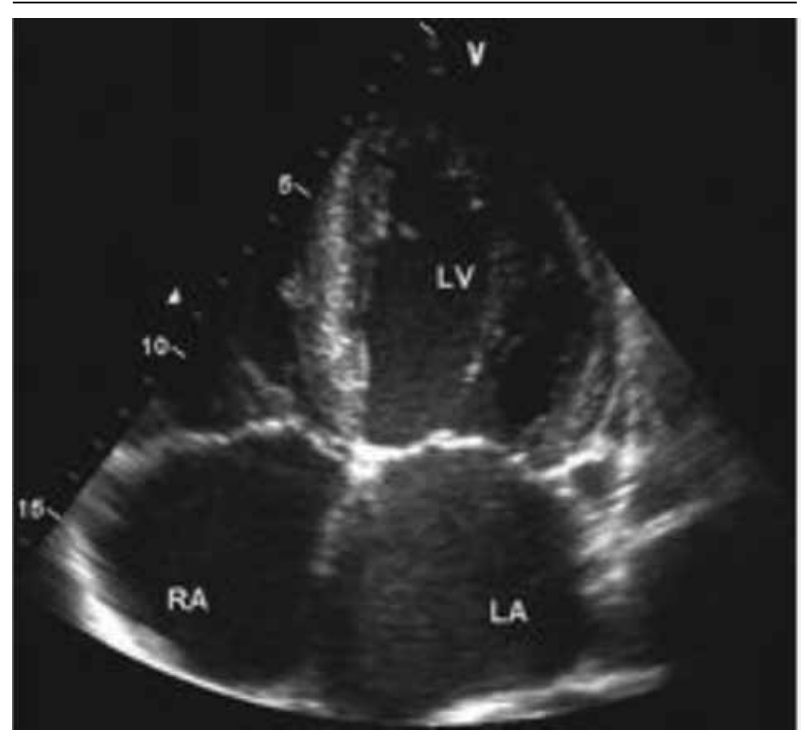

LA- Left Atrium, LV- Left Ventricle, RA- Right Atrium
Biological tests showed cholesterol and triglyceride levels of $250 \mathrm{mg} / \mathrm{dl}$ and $285 \mathrm{mg} / \mathrm{dl} / \mathrm{l}$, respectively, and elevated creatinine phosphokinase $(430 \mathrm{U} / \mathrm{l})$. Thyroid function test showed reduced T3 (60 ng/dl, normal: 80-180 $\mathrm{ng} / \mathrm{dl}$ ) and T4 (3.6 $\mu \mathrm{g} / \mathrm{dl}$, normal: 5-12 $\mu \mathrm{g} / \mathrm{dl})$ and elevated thyroid-stimulating hormone $(\mathrm{TSH}=135.5 \mathrm{mU} / \mathrm{l}$, normal: 0.5-5 mU/l), establishing a diagnosis of primary hypothyroidism. The thyroid was enlarged, heterogeneous, and multinodular by ultrasonographic imaging. The patient was positive for anti-thyroperoxidase and anti-microsome. The final diagnosis was Hashimoto thyroiditis.

The pulmonary edema was treated with oxygen inhalation, digoxin, diuretics, and angiotensin-converting enzyme inhibitors (ACEIs). Hormonal replacement therapy with levothyroxine was begun at an initial dose of $25 \mu \mathrm{g} /$ day, increasing over 9 months to $150 \mu \mathrm{g} /$ day, until the TSH levels normalized. Despite gradual symptomatic improvement, the echocardiography, performed 6 months after levothyroxine supplementation was initiated, revealed left ventricle ejection fraction of $45 \%$, and the patient was asked to take only ACEIs and omit digoxin and the diuretic. Three months after the $150-\mu \mathrm{g} /$ day dosage of levothyroxine was begun, the echocardiography showed a significant improvement in left ventricle systolic ejection fraction to $57 \%$ (Table 1). All other medications, including ACEIs, were withdrawn at this point. Echocardiography, performed twice at 6-month intervals then after echocardiography showed ejection fraction of $57 \%$, revealed ejection fractions of 56\% and 59\%, respectively, with the patient remaining symptom-free.

\section{Discussion}

Our case confirms previous reports concerning the potential reversibility of heart failure after substitutive hormone treatment $(2,8,9)$. The patient's young age at presentation with DCM led us to search for a reversible etiological factor. Additional findings of goiter, dry skin, and delayed relaxation of tendon reflexes led us to suspect coexistent hypothyroidism. Other similar cases have been reported primarily adults, with the youngest patient at age 20 years (7-9). We believe our case is unique, based on its presentation in a young subject aged 14 years.

Thyroid hormones interact with the sympathovagal balance but also act on peripheral vascular resistance. The effect of thyroid hormones on the cardiovascular system can be explained by the transcriptional regulation of genes that are implicated especially in contractile system synthesis. Rapid nongenomic effects of thyroid hormones on ionic channels in the cardiomyocyte membrane have recently been reported (10). The effects of thyroid hormone on the heart occur primarily through a change in protein synthesis. Some abnormalities of cardiac function in patients with thyroid dysfunction directly reflect the effects of thyroid hormone on calcium-activated ATPase and phospholamban, which are involved 


\begin{tabular}{lccl}
\hline Table 1. Comparison of Baseline Parameters of the Patient With That of Post Thyroxine Replacement Parameters. \\
\hline Parameters & Baseline & $\begin{array}{c}\text { After Levothyroxine, } \mathbf{1 5 0} \boldsymbol{\mu} \text { g/ Day } \\
\text { Treatment (12 weeks) }\end{array}$ & Reference Ranges \\
\hline TSH $^{\text {a }}$ & 135.5 & 10.5 & $0.5-5(\mathrm{mUI} / \mathrm{L})$ \\
Hemoglobin & 10.2 & 12.5 & $13-16 \mathrm{~g} / \mathrm{dl}$ \\
CPK & 430 & 90 & $<250(\mathrm{U} / \mathrm{L})$ \\
Ejection Fraction & $25 \%$ & $57 \%$ & $55-60 \%$ \\
\hline
\end{tabular}

a Abbreviations:TSH, Thyroid stimulating hormone; CPK, Creatine phosphokinase

primarily in the regulation of systodiastolic calcium concentrations in cardiomyocytes. Myocardial relaxation is effected by calcium uptake into the sarcoplasmic reticulum, mediated by calcium-activated ATPase. Thyroid hormone also modifies the expression of other ion channels, such as $\mathrm{Na}+/ \mathrm{K}+$-activated ATPase, $\mathrm{Na}+/ \mathrm{Ca}++$ exchanger, and some voltage-gated K+ channels (Kv1.5, Kv4.2, Kv4.3), thereby coordinating the electrochemical and mechanical responses of the myocardium (11). The majority of cardiac manifestations in hypothyroidism results from bradycardia, decreased myocardial contractility, and increased peripheral vascular resistance. (12). Pericardial effusion is the most frequent cardiac manifestation. Many patients with overt hypothyroidism have abnormal standard ECGs, including QT prolongation and flattening/inversion of the T wave (12), which reflect prolonged cardiac action potential. Sinus bradycardia with low voltage QRS complexes in our patient's ECG led to hypothyroidism as a possible etiology. The most frequent cardiac abnormality in patients with overt hypothyroidism is impairment of left ventricular (LV) diastolic function, which is characterized by slower myocardial relaxation and impaired early ventricular filling (13). LV systolic function is only marginally subnormal. Rawat et al. (14), in their study on overt hypothyroid patients, did not find any difference between severity of hypothyroidism and LV systolic function or LV size. Bhupathi et al. (15) found that systolic time intervals, such as pre-ejection period and ejection time, and diastolic functions, such as isovolumic relaxation time, were affected in hypothyroid children. However, ejection fraction (EF) and circumferential fiber shortening were not significantly affected. Other such cases that have presented with reversible DCM due to hypothyroidism (7-9) have responded to levothyroxine replacement therapy, ameliorating symptoms in 6 to 9 months. Our patient had a low EF of $25 \%$, which increased to $57 \%$ after levothyroxine treatment for 12 months ie, 12 weeks after normalization of TSH. Hypothyroidism itself is one of the risk factors for atherosclerosis (16). Alterations in $\mathrm{T}_{3}$-mediated gene expression lead to various cardiac manifestations in hypothyroidism (17). In hypothyroidism, although cardiac output is reduced, heart failure is relatively rare, because there is lower oxygen demand in the periphery (18). In a study by Rodondi et al., subclinical hypothyroidism was associated with an increased risk of congestive heart failure among older adults with a TSH level of $\geq 7.0 \mathrm{mIU} / \mathrm{L}$ but not with other cardiovascu- lar events or mortality (19). No similar observations were noted in young subjects. The baseline TSH level in our subject was $135.5 \mathrm{mIU} / \mathrm{L}$.

In our patient, the family history argued against inherited causes of dilated cardiomyopathy. There was no history of drug abuse or alcohol or toxic substance addiction. The personal history and clinical exam ruled out nutritional deficiency, and negative HIV and HCV serologies eliminated potential viral causes of dilated cardiomyopathy. Our observations highlight the importance of hormone dosage in the first assessment of DCM, even in the absence of major symptoms of $\mathrm{TH}$, because clinical presentation is not always obvious and because the diagnosis can only be made by thyroid function testing. Fortunately, the diagnosis of hypothyroidism was clinically evident in our patient and confirmed by the thyroid function test.

The challenge is to determine whether TH has an occasional association with DCM or is a cause of it (17). Bezdah et al. (2) and Khochtali I et al. (8) have suggested that hypothyroidism should be systematically evoked when DCM is diagnosed. The improvement in cardiac function after hormone treatment in our patient implicates hypothyroidism in the genesis of DCM. However, the earliest age of presentation of DCM in hypothyroidism in the literature is 20 years (8). Our case report highlights this unusual occurrence of hypothyroidism-induced, reversible DCM at age 14 years.

DCM is typically an idiopathic disease with a progressive course and an irreversible, poor prognosis and outcome. In contrast, in some cases, DCM can be secondary to various causes, such as hypothyroidism, and hormone treatment with levothyroxine can significantly improve myocardial function. Hence, we feel strongly that thyroid function tests should be performed systematically in all patients with DCM to rule out hypothyroidism. Most commonly, DCM becomes clinically apparent in the third or fourth decade of life. However, one needs to be alert for such occurrences in young subjects with hypothyroidism.

\section{Acknowledgments}

All the authors would extend their heartfelt thanks to Dr Jagadeesh Tangudu, M Tech, MS, PhD, Sowmya Jammula, M Tech for their immense and selfless contribution towards manuscript preparation, language editing and final approval of text. 


\section{Financial Disclosure}

None declared.

\section{Funding/Support}

None declared.

\section{References}

1. Elliott P. Cardiomyopathy. Diagnosis and management of dilated cardiomyopathy. Heart. 2000;84 (1):106-12.

2. Bezdah L, Slimène $H$, Kammoun M, Haddad A, Belhani A. [Myocardiopathie dilatee dorigine myxoedemateuse]. Ann Cardiol Angeiol. 2004;53:217-20.

3. Danaher PJ, Cao MK, Anstead GM, Dolan MJ, DeWitt CC. Reversible dilated cardiomyopathy related to amphotericin B therapy. JAntimicrob Chemother. 2004;53 (1):115-7.

4. Derish M, Eckert K, Chin C. Reversible cardiomyopathy in a child with Addison's disease. Intensive Care Med.1996;22 (5) :460-3.

5. Kantharia BK, Richards HB, Battaglia J. Reversible dilated cardiomyopathy: an unusual case of thyrotoxicosis. Am Heart J. 1995;129 (5):1030-2.

6. Quigg RJ, Om A. Reversal of severe cardiac systolic dysfunction caused by pheochromocytoma in a heart transplant candidate.J Heart Lung Transplant. 1994;13 (3):525-32.

7. Zondek H. Das myxodemherz. Munch Med Wochenschr. 1918;65:1180-83.

8. Khochtali I, Hamza N, Harzallah O, Hamdi S, Saad J, Golli M, et al. Reversible dilated cardiomyopathy caused by hypothyroidism. Int Arch Med. 2011;4:20.
9. Ladenson PW, Sherman SI, Baughman KL, Ray PE, Feldman AM. Reversible alterations in myocardial gene expression in a young man with dilated cardiomyopathy and hypothyroidism. Proc Natl Acad Sci U S A. 1992;89 (12) :5251-5.

10. Lorcy Y, Klein M. [Troubles cardiovasculaires dorigine thyroidienne]. EMC-Cardiologie-Angeiologie. 2005;2 (2):127-35.

11. Klein I, Ojamaa K. Thyroid hormone and the cardiovascular system. N Engl J Med. 2001;344 (7) :501-9.

12. Klen I, Ojamaa K. Cardiovascular system in hypothyroidism. In: Braverman LE, Utiger RD, eds. Werner \& Ingbars The Thyroid: A Fundamental and Clinical Text. Philadelphia, editor.; 2000.

13. Wieshammer S, Keck FS, Waitzinger J, Henze E, Loos U, Hombach $\mathrm{V}$, et al. Acute hypothyroidism slows the rate of left ventricular diastolic relaxation. Can J Physiol Pharmacol. 1989;67 (9): 1007-10.

14. Rawat B, Satyal A. An echocardiographic study of cardiac changes in hypothyroidism and the response to treatment. Kathmandu Univ Med J (KUMJ). 2004;2 (3):182-7.

15. Bhupathi R, Kothari SS, Gupta AK, Menon PS. Cardiac function in hypothyroid children: effect of replacement therapy. Indian Pediatr.1999;36 (8):779-84.

16. Ichiki T. Thyroid hormone and atherosclerosis. Vascul Pharmacol. 2010;52 (3-4) :151-6.

17. Klein I, Danzi S. Thyroid disease and the heart. Circulation. 2007;116 (15) :1725-35.

18. Stanescu C, Branidou K, Ranetti EA. Heart failure and dilated cardiomyopathy associated with severe longstanding untreated hypothyroidism. Rom J Intern Med. 2007;45 (1):77-83.

19. Rodondi N, Newman AB, Vittinghoff E, de Rekeneire N, Satterfield S, Harris TB, et al. Subclinical hypothyroidism and the risk of heart failure, other cardiovascular events, and death. Arch Intern Med. 2005;165 (21):2460-6. 